Available online at https://jurnal.stmikroyal.ac.id/index.php/jurdimas

\title{
PENERAPAN TEKNOLOGI INFORMASI PENENTUAN PRIORITAS PENERIMA BANTUAN LANGSUNG TUNAI (BLT) DESA PAGAR JATI
}

\author{
Anita Sindar Sinaga ${ }^{{ }^{*}}$, Murni Marbun ${ }^{1}$, Arjon Samuel Sitio ${ }^{1}$ \\ ${ }^{1}$ Teknik Informatika, STMIK Pelita Nusantara \\ email:*haito_ita@yahoo.com
}

\begin{abstract}
The pandemic has caused the economy to decline drastically, even many residents have lost their sources of livelihoods. The government directly disbursed funds in the form of Direct Cash Assistance. The problem that arose was the suspicion of injustice for the villagers who received BLT. There is a need for a transparent system to inform the criteria for BLT recipients. The more criteria for poor and vulnerable families that were met, the priority for BLT village fund recipients. BLT priority assessment based on the aspect of the criteria that apply by law is implemented using PhpMyadmin. The development of a web-based information system made it easier to inform villagers of the names of BLT priority recipients based on the reasons that had been collected and then ranked. The resulting system helps employees of the Pagar Jati Village office to inform BLT recipients in a technological system built with the water fall method including data collection, problem analysis, design, testing and system evaluation.
\end{abstract}

Keywords: devotion; information systems; priority setting; web based

\begin{abstract}
Abstrak: Pendemi mengakibatkan perekonomian menurun drastis, bahkan banyak warga yang kehilangan sumber mata pencaharian. Pemerintah secara langsung mengucurkan dana dalam bentuk Bantuan Langsung Tunai (BLT). Permasalahan yang timbul yaitu kecurigaan adanya ketidakadilan bagi warga desa penerima BLT. Perlu adanya sistem yang transparan menginformasikan kriteria penerima BLT. Semakin banyak kriteria keluarga miskin dan rentan yang dipenuhi, menjadi prioritas penerima BLT dana desa. Penilaian prioritas BLT berdasarkan aspek kriteria yang berlaku secara undang-undang diimplementasikan menggunakan PhpMyadmin. Pengembangan sistem informasi berbasis web mempermudah menginformasikan pada warga desa nama-nama penerima prioritas BLT berdasarkan alasan-alasan yang sudah dikumpulkan lalu diranking. Sistem yang dihasilkan membantu pegawai kantor Desa Pagar Jati menginformasikan penerima BLT secara sistem teknologi yang dibangun dengan metode water fall meliputi pengumpulan data, analisa permasalahan, perancangan, pengujian dan evaluasi sistem.
\end{abstract}

Kata kunci: berbasis web; penentuan prioritas; pengabdian; sistem informasi 
Available online at https://jurnal.stmikroyal.ac.id/index.php/jurdimas

\section{PENDAHULUAN}

Penerapan Teknologi Informasi (TI) menjadi sebuah cara atau metode melakukan transparansi bidang tugas pertanggungjawaban. Teknologi memudahkan siapapun berinteraksi untuk mendapatkan informasi terkini (Sinaga, 2020). Pemanfaatan TI yang terbuka untuk umum dan dapat diakses oleh siapapun memungkinkan pengawasan terhadap kinerja pemerintah. Teknologi informasi tidak hanya terbatas pada teknologi komputer (perangkat keras dan perangkat lunak) yang akan digunakan untuk memproses dan menyimpan informasi, melainkan juga mencakup teknologi komunikasi untuk mengirim informasi. Teknologi komputer merupakan teknologi yang berhubungan dengan perangkat komputer seperti printer, pembaca sidik jari, CD-ROM, prosesor, disk, dan lain-lain. Komputer termasuk mesin serbaguna yang dapat digunakan untuk keperluan pengolahan data apa saja menjadi informasi yang berguna (Salamah, Fadhli \& Kusumanto, 2020). Hal ini dimungkinkan karena komputer dapat dikendalikan oleh program yang terdiri atas sederetan instruksi. Komputer akan bertindak sesuai instruksi yang diterimanya dari program. Dengan kata lain komputer akan bertindak sesuai keinginan pembuat program.

Pada masa pendemi pemerintah gencar memberikan Bantuan Dana Langsung (BLT). Bantuan Langsung Tunai yang disingkat BLT merupakan program bantuan pemerintah berjenis pemberian uang tunai atau beragam bantuan lainnya, baik bersyarat maupun tidak bersyarat. Dalam buku Panduan Pendataan Penerima BLT-Dana desa, dijelaskan kriteria calon penerima BLTdana desa bermanfaat membantu terlaksananya pendataan dan penyaluran BLT-dana desa yang efektif, efisien, dan tepat sasaran (Analisis, 2020).

Untuk menjamin bantuan disalurkan secara adil dan merata maka pemerintah desa melibatkan seluruh pihak termasuk organisasi warga desa untuk berpartisipasi memonitoring jalannya pembagian dana BLT (Aisyah, Maulana, Rahmalina \& Firdian, 2020).

Timbulnya kecurigaan dan sikap protes warga desa terhadap daftar penerima dana BLT yang tidak tepat sasaran mendorong perangkat desa untuk mengevaluasi nama-nama penerima BLT berdasarkan kriteria penerima dana. Warga desa menginginkan transparansi pencairan dana dan secara merata bagi masyarakat yang tidak berpenghasilan (Analisis, 2020). Dari permasalahan yang muncul, membangun sebuah sistem informasi untuk menentukan prioritas penerima BLT (Arjon, 2020).

Sistem yang dihasilkan ditujukan untuk membantu para pegawai kantor desa Pagar Jati menampilkan penerima BLT secara sistem berbasis web (Sinaga, Sitio \& Sijabat, 2020). Dengan adanya sistem ini maka pertanyaan-pertanyaan warga desa mengenai ketidakadilan pembagian BLT dapat diatasi melakui penilaian yang dilakukan oleh sistem (Mufida, 2020).

Sistem informasi dikembangkan berbasis web, yaitu perangkat hardware terkoneksi secara online. Nantinya warga desa dapat mencari informasi nama-nama yang menerima BLT dengan terlebih dahulu menginput data-data yang diminta sistem. Sistem yang dirancang bekerja sesuai metode yang telah dikembangkan sehingga dari ouput pengisian data-data warga desa, sistem memberikan luaran laporan nama-nama yang berhak menerima BLT sesuai perangkingan (Maun, 2020). 
Available online at https://jurnal.stmikroyal.ac.id/index.php/jurdimas

\section{METODE}

Metode yang dipergunakan dalam kegiatan ini adalah diskusi dan pelatihan dengan beberapa aparatur desa serta warga desa berkaitan dengan BLT Tahap 1 dan 2 di Kantor desa Pagar Jati, Lubuk Pakam. Pagar Jati merupakan salah satu kelurahan yang ada di kecamatan Lubuk Pakam, Kabupaten Deli Serdang, provinsi Sumatra Utara, Indonesia.

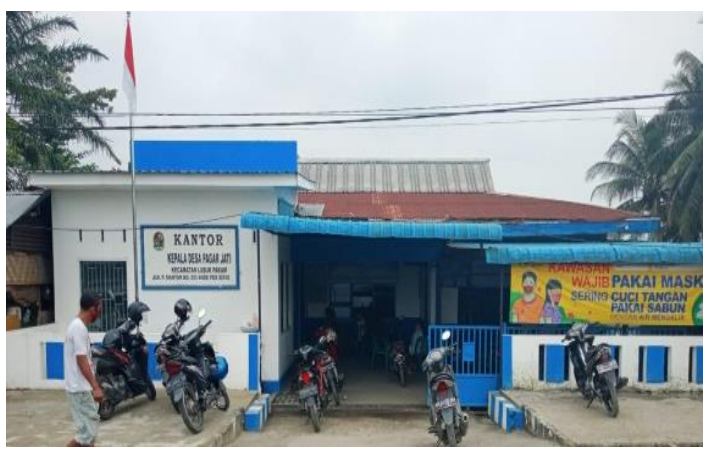

Gambar 1. Kantor Desa Pagar Jati

Adapun peran kegiatan dalam pengabdian :

1) Tim pengabdian berperan melakukan survei dan wawancara, penyusunan rencana kegiatan, pembagian tugas, pelaksana kegiatan, sosialisasi serta melaporkan hasil kegiatan.

2) Mahasiswa berperan mengolah data, inplementasi rancangan dan sosialisasi hasil.

3) Aparatur desa berperan sebagai sumber wawancara, memberikan masukan pada kegiatan, melakukan evaluasi.

\section{Analisa Permasalahan}

1) Tim pengabdian secara informal melakukan wawancara dengan warga desa, fokus pada kebutuhan warga yang berkaitan dengan sistem yang dibangun.

2) Tim pengbadian dari STMIK Pelita
Nusantara mengajukan surat permohonan melaksanakan pengbdian sesuai pokok permasalahan di Desa Pagar Jati.

3) Tim pengbadian yang terdiri dari 1 ketua dan 2 anggota mengajukan surat tugas pada LPPM STMIK Pelita Nusantara.

\section{Analisa Sistem}

Tugas utama analisa sistem adalah menemukan kelemahan-kelemahan dari sistem yang berjalan sehingga dapat diusulkan perbaikan. Langkah-langkah dasar yang dilakukan :

1) Identify, yaitu mengidentifikasi masalah.

2) Understand, yaitu memahami kerja dari sistem yang ada

3) Analyze, yaitu menganalisis system

4) Report, yaitu membuat laporan hasil analisis.

\section{Penyusunan Kebutuhan}

Tahap penyusunan kebutuhan dan perancangan website:

a. Identifikasi sistem pembagian BLT yang sedang berjalan.

b. Identifikasi permasalahan yang dihadapi warga Desa penerima BLT dan yang tidak menerima BLT.

c. Menganalisis pengaruh teknologi informasi dalam transparansi BLT.

d. Mendeskripsikan kebutuhan rancangan sistem informasi.

e. Pengimplementasian rancangan.

\section{Evaluasi dan Pengujian}

Tahap selanjutnya melakukan Evaluasi, dengan memperhatikan kualitas SDM (skill) pegawai kantor Desa Pagar Jati. Bertujuan agar sistem yang dihasilkan dapat dioperasikan secara maksimal maka tim pengbadian memberikan arahan mempersiapkan skill sebagai operator sistem. 
Available online at https://jurnal.stmikroyal.ac.id/index.php/jurdimas

Pada tahap pengujian, diperkenalkan sistem yang dihasilkan, untuk itu pegawai yang akan bertindak sebagai operator atau admin sistem mendapat training singkat pengoperasian sistem. Sistem yang dihasilkan berbasis web, yaitu pengoperasian proses input ouput yang langsung terkoneksi dengan link web site.

\section{PEMBAHASAN}

Calon penerima BLT-Dana desa adalah keluarga miskin baik yang terdata dalam Data Terpadu Kesejahteraan Sosial (DTKS) maupun yang tidak terdata (exclusion error) yang memenuhi kriteria tidak mendapat bantuan PKH/BPNT/ pemilik Kartu Prakerja; Mengalami kehilangan mata pencaharian (tidak memiliki cadangan ekonomi yang cukup untuk bertahan hidup selama tiga bulan ke depan); Mempunyai anggota keluarga yang rentan sakit menahun/kronis.

Analisis sistem yang sedang berjalan adalah penguraian dari suatu sistem informasi yang utuh ke dalam bagian-bagian komponennya dengan maksud untuk mengidentifikasi dan mengevaluasi permasalahan, kesempatan, hambatan-hambatan yang terjadi dan kebutuhan-kebutuhan yang diharapkan sehingga diusulkan perbaikan-perbaikan.

Analisis yang telah dilakukan dalam kebutuhan perangkat lunak untuk menjalankan agar aplikasi ini dapat berjalan dengan baik, yaitu Sistem Operasi Windows XP dan DBMS menggunakan $M y S Q L$.

Penentuan penerima dana BLT didukung penilaian dari Aspek dan Kriteria. Setiap Aspek dibagi atas kriteria yaitu Aspek Profil terdiri dari kriteria Aspek profil terdiri dari kriteria NIK, Status Kepala Keluarga, Pekerjaan, Usia,
Pendidikan dan Kesehatan. Aspek bantuan dikategorikan untuk kriteria Bantuan Sosial, Bantuan Pemerintah Pusat, Bantuan Pemerintah Provinsi, Bantuan Pemerintah desa, Menerima JPS, Tidak Menerima JPS. Aspek kondisi meliputi kriteria Miskin Tidak Terdata, Miskin Tidak Berpenghasilan, Miskin dan Rentan, Keterangan Domisili.

\begin{tabular}{lcr}
\multicolumn{1}{c}{ Hasil } & rancangan & dibangun \\
menggunakan & PHPMyAdmin & dengan \\
pengelolaan & database & Xampp,
\end{tabular}
Penginputan data-data warga desa pada sistem dilakukan oleh operator yaitu pegawai kantor desa Pagar Jati, dapat pada gambar 2 .

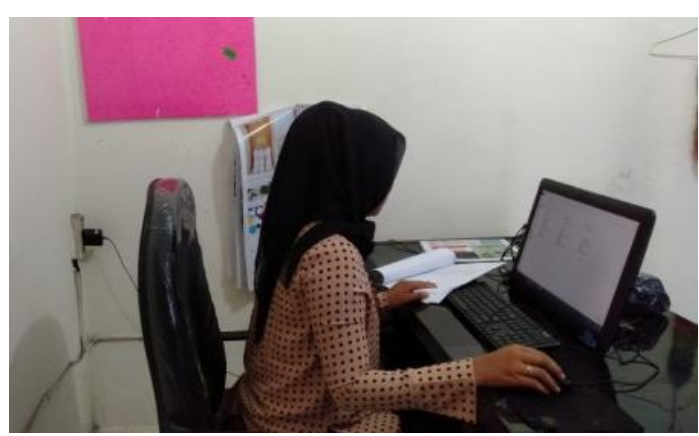

Gambar 2. Update Data Warga Desa

Bentuk Form Menu Utama akan tampil bila username dan password valid. Dashboard merupakan tampilan awal pada saat aplikasi dijalankan.Tampilan Dahboard, Menu Utama dapat dilihat pada Gambar 3.

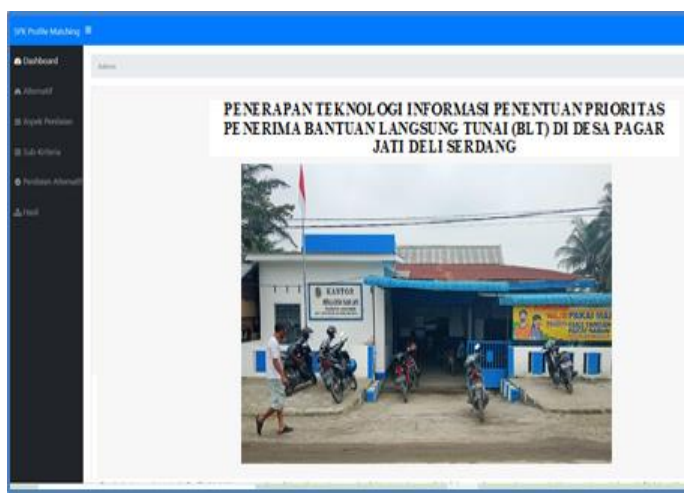

Gambar 3. Form Dahboard Sistem 
Available online at https://jurnal.stmikroyal.ac.id/index.php/jurdimas

Tahapan pengoperasian Sistem Penentuan Prioritas Bantuan Langsung Tunai di desa Pagar Jati dimulai admin melakukan login, menginput username dan password. Apabila username dan password valid maka aplikasi dapat dilanjutkan dengan menentukan variabel data-data yang dibutuhkan pada Menu Data Penduduk dan Menu Penentuan Penerima BLT. Hasil penginputan diolah sistem, hasil perhitungan dapat dilihat pada Menu Hasil. Menu hasil menampilkan nama-nama prioritas penerima BLT.

Form Data Penduduk dirancang untuk menginput data penduduk calon penerima BLT. Pada menu ini terdapat tombol edit dan hapus. Form Data Penduduk menampilkan data penduduk yang akan dinilai dapat dilihat pada Gambar 4. Semakin banyak kriteria yang memungkinkan warga Desa menerima BLT dengan kondisi-kondisi yang sangat mendukung menjadi aspek utama dalam penilaian prioritas penerima BLT, pada Tabel 1 dan Tabel 2.

Menu Penentuan merupakan halaman menampilkan kode aspek penentuan penerima BLT, nama aspek penilaian dan bobot dari setiap penilaian. Pada menu ini terdapat tombol edit dan hapus. Tampilan Menu Penilaian dapat dilihat pada Gambar 5.

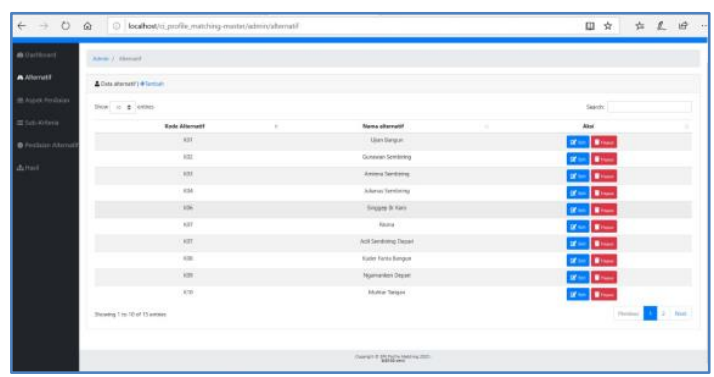

Gambar 4. Form Penginputan Data Penduduk
Tabel 1. Penilaian Penerima BLT 1

\begin{tabular}{ll}
\hline \multicolumn{1}{c}{ Kriteria } & \multicolumn{1}{c}{ Sub kriteria } \\
\hline NIK & $\begin{array}{l}\text { Warga Desa } \\
\text { Tidak warga Desa }\end{array}$ \\
\hline $\begin{array}{l}\text { Status } \\
\text { Kepala }\end{array}$ & $\begin{array}{l}\text { Menikah kepala keluarga } \\
\text { Tidak menikah }\end{array}$ \\
\hline Pekerjaan & $\begin{array}{l}\text { Berpenghasilan tetap } \\
\text { Tidak berpenghasilan tetap } \\
\text { Tidak bekerja }\end{array}$ \\
\hline Usia & $\begin{array}{l}\text { Lanjut usia mulai dari 70 } \\
\text { tahun } \\
\text { Usia Produktif }\end{array}$ \\
\hline \multirow{2}{*}{ Pendidikan } & $\begin{array}{l}\text { Lulus Sekolah Menengah } \\
\text { Atas sederajat } \\
\text { Lulus SD SMP }\end{array}$ \\
\hline Kesehatan & $\begin{array}{l}\text { Rentan sakit mena- } \\
\text { hun/kronis }\end{array}$ \\
\hline
\end{tabular}

Tabel 2. Penilaian Penerima BLT 2

\begin{tabular}{|c|c|}
\hline Kriteria & Penjelasan \\
\hline Bantuan So- & $\begin{array}{l}\text { Bantuan sosial } \\
\text { Kementerian Desa, } \\
\text { Bantuan sosial Dinas } \\
\text { sosial }\end{array}$ \\
\hline $\begin{array}{l}\text { Bantuan } \\
\text { Pemerintah } \\
\text { Pusat }\end{array}$ & $\begin{array}{l}\text { Sumber dana dari } \\
\text { Pemerintah Pusat }\end{array}$ \\
\hline $\begin{array}{l}\text { Bantuan } \\
\text { Pemerintah } \\
\text { Provinsi }\end{array}$ & $\begin{array}{l}\text { Sumber dana dari } \\
\text { Pemerintah Provinsi }\end{array}$ \\
\hline $\begin{array}{l}\text { Bantuan } \\
\text { Pemerintah } \\
\text { Desa } \\
\end{array}$ & $\begin{array}{l}\text { Sumber dana dari } \\
\text { Pemerintah Desa }\end{array}$ \\
\hline $\begin{array}{l}\text { Menerima } \\
\text { Jaring } \\
\text { Pengaman } \\
\text { Sosial (JPS) }\end{array}$ & $\begin{array}{l}\text { Sumber dana sesuai } \\
\text { ketentuan JPS }\end{array}$ \\
\hline $\begin{array}{l}\text { Tidak } \\
\text { Menerima } \\
\text { Jaring } \\
\text { Pengaman } \\
\text { Sosial (JPS) }\end{array}$ & $\begin{array}{l}\text { Sumber dana sesuai } \\
\text { ketentuan JPS }\end{array}$ \\
\hline
\end{tabular}




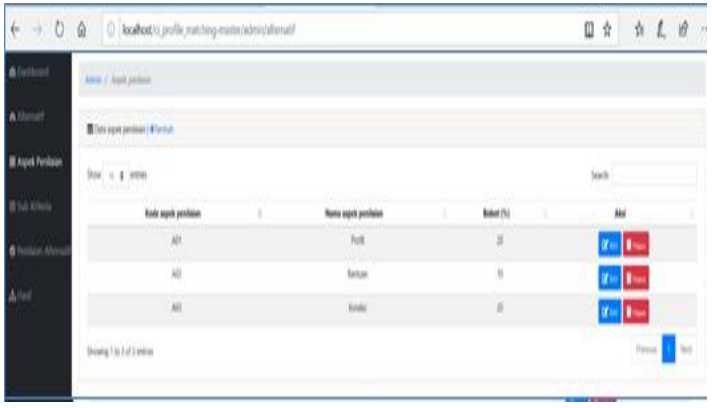

Gambar 5. Form Penentuan Penerima BLT

\section{SIMPULAN}

Sistem informasi memberi
manfaat pada sistem yang akan
menggunakan rancangan aplikasi.
Kelebihan sistem yang dihasilkan dapat
membantu pegawai kantor desa dalam
menentukan prioritas penerima BLT
berdasarkan proses sistem berbasis
teknologi.

\section{UCAPAN TERIMA KASIH}

Ucapan terima disampaikan kepada Kepala desa Pagar Jati Lubuk Pakam, yang telah mendukung terselenggaranya program pelaksanaan pengabdian kepada masyarakat.

\section{DAFTAR PUSTAKA}

Aisyah, H., Maulana, I. T., Rahmelina, L., \& Firdian, F. (2020).
Implementasi teknologi positif dalam meningkatkan kualitas pendidikan. 3(1), 86-94.

Analisis, H. (2020). Pengutamaan Penggunaan Dana Desa: Bantuan Langsung Tunai Desa 1.

Arjon, S. (2020). Pemanfaaatan IT Dalam Pelaksanaan Ujian Berbasis Komputer Pada Sma Negeri 2 Perbaungan. Abdimasya: Jurnal Pengabdian Pada Masyarakat, 1(1), 1-9.

Maun, C. E. F. (2020). Miskin Terkena Dampak Covid-19 Di Desa Talaitad Kecamatan Suluun. 116.

Mufida, A. (2020). Polemik Pemberian Bantuan Sosial Di Tengah Pandemic Covid 19. 4, 159-166.

Mukminin, A., \& Waluyo, E. (2010). Penerapan Pembelajaran Berbasis Komputer sebagai Dasar Pengenalan Teknologi Informasi pada Guru Taman Kanak-kanak di Kota Semarang. Jurnal Abdimas, 14(2).

Salamah, I., Fadhli, M., \& Kusumanto, R. (2020). Pemanfaatan Internet Sebagai Sumber Belajar Bagi Guru Sd Negeri 130 Palembang. 3(2), 99-104.

Sinaga, A. S., Sitio, A. S., \& Sijabat, P. (2020). Pengenalan Dasar Pengkodingan Secara Daring pada SMK Pemda Lubuk Pakam. Abdimas Universal, 2(2), 95-99. 